\title{
Relationship of being threatened or injured with a weapon in school with suicidal ideation and attempt among school students: a school-based study in Zhejiang Province, China
}

Hao Wang ${ }^{1}$, Huaidong Du ${ }^{2,3}$, Fiona Bragg ${ }^{2}$, Jieming Zhong ${ }^{1}$ and Min $\mathrm{Yu}^{{ }^{*}}$

\begin{abstract}
Background: Suicide is the second leading cause of death among 15-29 year old youths globally, and the third most common external cause of death in China. School bullying can cause serious consequences among adolescents, including psychosocial problems, low self-esteem and post-traumatic stress disorder. Most studies examining the associations between being bullied in school and suicide are from Western, developed countries. Moreover, few studies focus on being threatened or injured with a weapon, which may cause serious body injury. Our study aimed to explore the relationship of being threatened or injured with a weapon in school with suicidal ideation and attempt among middle and high school students in Zhejiang Province, China.
\end{abstract}

Methods: A cross-sectional study of 23,543 students in grades 7-12 from 442 schools was carried out through an anonymous self-administered questionnaire between April and May 2017. Multivariable logistic regression models were used to examine the relationship of being threatened or injured with a weapon in school with suicidal ideation and attempt.

Results: $51.3 \%$ of participants were boys, and mean (SD) age was 15.6 (1.7) years. The overall prevalence of suicidal ideation and attempt were $16.1 \%(95 \% \mathrm{Cl}$ : 15.3-16.9) and 3.6\% (95\%Cl: 3.3-4.0), respectively. Prevalence was higher among girls than boys (ideation: $19.1 \%$ vs. $13.3 \%$. attempt: $4.4 \%$ vs. $2.9 \%$ ). $13.2 \%$ of students reported being threatened or injured with a weapon in school in the past 12 months ( $95 \% \mathrm{Cl}$ : 11.9-14.5), higher among boys than girls (15.7\% vs. 10.5\%), and among rural students than urban students (13.9\% vs. 11.6\%). After adjustment for socio-demographic status, lifestyle factors, academic performance, self-reported health and mental health, the odds ratios for suicidal ideation and attempt among students who reported being threatened or injured with a weapon were $1.46(1.31-1.61)$ and $1.68(1.31-2.13)$ respectively, as compared with those who did not report being threatened or injured.

Conclusions: Preventive measures for physical bullying in school need to be reinforced in China. Being threatened or injured with a weapon is associated with both suicidal ideation and attempt among middle and high school students. Suicide prevention should be an important component of psychological interventions for threatened or injured students.

Keywords: Suicidal ideation, Suicidal attempt, Threatened, Adolescents, Factors

\footnotetext{
* Correspondence: myu@cdc.zj.cn

${ }^{1}$ Department of NCDs Control and Prevention, Zhejiang Provincial Center for

Diseases Control and Prevention, \#3399 Binsheng road, Binjiang District,

Hangzhou 310051, Zhejiang Province, China

Full list of author information is available at the end of the article
}

(c) The Author(s). 2018 Open Access This article is distributed under the terms of the Creative Commons Attribution 4.0 International License (http://creativecommons.org/licenses/by/4.0/), which permits unrestricted use, distribution, and reproduction in any medium, provided you give appropriate credit to the original author(s) and the source, provide a link to the Creative Commons license, and indicate if changes were made. The Creative Commons Public Domain Dedication waiver (http://creativecommons.org/publicdomain/zero/1.0/) applies to the data made available in this article, unless otherwise stated. 


\section{Background}

Suicide is a serious public health problem worldwide and is responsible for more than 0.8 million deaths annually. In 2012 , approximately $76 \%$ of deaths due to suicide occurred in low- and middle-income countries including China [1]. Suicide is the second leading cause of death among 15-29 year olds globally [1]. There were nearly 120.7 thousand deaths from suicide in China in 2012, accounting for $15 \%$ of global suicide deaths [1]. Suicide rates in China decreased significantly during the past 30 years $[2,3]$. However, it remains the third most common external cause of death, following road traffic accidents and falls [4]. Between 2006 and 2016, mortality due to suicide among children and adolescents aged 1014 years in urban areas increased rapidly, from 0.24 to 0.98 per 100,000 , and in rural areas from 0.97 to 0.85 per 100,000 . Mortality due to suicide among adolescents aged 15-19 years decreased from 1.80 to 1.56 per 100,000 in urban areas, and from 3.47 to 2.52 per 100,000 in rural areas [5]. In Chinese traditional culture, one should not deliberately hurt oneself. As a Chinese saying states, the body, hair and skin have all been received from the parents, and so one doesn t dare damage them; this is the beginning of filial piety. While in Western countries, mental health disorders account for more than $90 \%$ of suicides, only about half of suicides were related to mental health disorders in China [6]. Easy access to pesticides increases the risk of suicide in rural areas of China [7], while lack of medical care and facilities increases the possibility of completed suicide [8]. Hence, it is necessary to study the epidemiological profile of suicide behaviours among Chinese students.

Suicidal ideation and suicide attempt are recognized as important predictors and indicators of subsequent completed suicide $[9,10]$. A meta-analysis including 320,375 students included in 40 studies conducted in China found that the prevalence of suicidal ideation among high school students was 18.0\% (95\%CI: 16.6-19.5) [11]. The epidemiology of suicidal ideation and attempt involves a large number of risk factors, including sociodemographic factors (e.g., gender, family income and family structure) [12, 13], behavioural factors (cigarette use, alcohol use, illicit drug use, inadequate physical activity and ever having sexual intercourse) [14-16], mental health (e.g., sadness, loneliness and depression) [15, $17,18]$, poor physical health $[19,20]$ and poor academic performance [21].

School bullying refers to any unwanted aggressive behaviours towards one youth by another youth or group of youths, who are not siblings or current dating partners, involving an observed or perceived power imbalance. These behaviours are repeated, or have the potential to be repeated, over time [22]. Bullying may comprise physical or non-physical bullying. The latter includes verbal bullying (e.g., verbal insulting, slandering, gossiping and taunting etc.) and non-verbal bullying (e.g., obscene gesture, hiding belongings, deliberate excluding from a group or activity, and social marginalization etc.) [23]. School bullying may have serious consequences among adolescents, including psychosocial problems (e.g., depression, loneliness and anxiety) [24, 25], low self-esteem [26] and post-traumatic stress disorder [27].

Physical bullying among adolescents is less normative compared to other types of bullying and therefore associated with more severe outcomes [28]. Being threatened or injured with a weapon is one of the most serious forms of physical bullying [29]. The prevalence of being threatened or injured with a weapon on school property among high school students ranged from 4.8\% (Massachusetts) to $12.8 \%$ (Louisiana) in the USA in 2017 [30], but little is known about the epidemiological profile of being threatened or injured with a weapon among students in China.

More recently, a large number of articles have focused on the effect of being bullied in school on adolescent suicide [31]. However, most studies are from Western, developed countries [32-35]. Moreover, the association of being bullied in school with risk of suicidality is still controversial. Some studies have observed positive associations [34, 35], while others have found null associations [36, 37]., A latest longitudinal study indicated that the association between victimization and suicide behaviours relates to the specific type of victimization. Relational, but not verbal or physical, victimization significantly increased the likelihood of experiencing suicidal ideation. Conversely, physical victimization, but not verbal or relational, significantly increased the likelihood of suicide attempt [38]. A study of 20,509 high school students from China found that being bullied was associated with an increased risk of suicidal ideation. However, this study did not explore the relationship between being bullied and suicidal attempt [39]. Furthermore, few studies have examined the associations of being threatened or injured with a weapon, which will additionally cause direct body injury. The current study was designed with the aim of examining the relationship of being threatened or injured with a weapon in school and suicidal ideation with attempt among students in Zhejiang Province.

\section{Participants and methods}

\section{Survey design and participants}

Details of the study design, sampling, and procedure have been described previously [40]. In brief, a three-stage sampling design was utilized. In stage one, 30 counties were sampled randomly from all 90 counties. In stage two, 10 classes of middle school, 5 classes of academic high school, and 5 classes of vocational high school were selected randomly within each chosen county. In stage 
three, all students in the chosen classes were invited to participate in the study. The survey questionnaire was modelled on existing surveys including the Youth Risk Behaviour Survey (YRBS), conducted by the Centers for Disease Control and Prevention (CDC) [41], and the international Global School-based Student Health Survey, supported by the World Health Organization [42]. Survey questions addressed demographic characteristics (including age, gender, parental educational level, and parental marital status), tobacco and alcohol use, physical activity, violence, suicidal behaviours, and sexual behaviours. Strict quality control measures were undertaken to ensure data quality. Participants were asked to complete a questionnaire in the classroom in the absence of school teachers, with a distance of at least one meter between students' seat. All participants were advised, by trained interviewers, that there were no so-called "correct" or "incorrect" answers, that the questions should be answered honestly and accurately, and that their answers were unrelated to their academic performance and would be kept confidential (including from their school teachers and parents). The questionnaire was put into sealed box by participants after completion.

\section{Measures \\ Outcome variables}

Suicidal ideation was assessed by a yes/no response to the question "During the past 12 months, did you ever seriously consider attempting suicide?" Suicidal attempt was assessed through the question: "During the past 12 months, how many times did you actually attempt suicide?" Response options included: "None", "1 time", "2-3 times", "4-5 times" and " 6 or more times." Suicidal attempt was defined as at least once in the past 12 months.

\section{Exposure variables}

Being threatened or injured with a weapon in school was assessed with the question: "During the past 12 months, how many times has someone threatened or injured you with a weapon such as a club or knife on school property?" Answer options included: "None", "1 time", "2-3times", "4-5 times", "6-7 times", "8-9 times", "10-11 times" and "12 or more times". Students who reported one or more time were classified as being threatened or injured with a weapon.

\section{Covariates}

Covariate question and response options (including parental education, parental marital status, cigarette use, alcohol use, physical activity, academic performance, selfreported health, sexual experience, loneliness) have been reported previously [40, 43]. Sadness was assessed through the question: "During the past 12 months, did you ever feel so sad or hopeless almost every day for two weeks or more in a row that you stopped doing some usual activities?" Answer options were "yes" and "no".

\section{Statistical analysis}

Statistical analyses were performed using SAS software V.9.3. A weighting factor was applied at the student-level to adjust for non-response and for the varying probabilities of selection. The weight used for estimation in this survey is given by: $\mathrm{W}=\mathrm{W} 1 \times \mathrm{W} 2 \times \mathrm{f} 1 \times \mathrm{f} 2$. $\mathrm{W} 1=$ the inverse of the probability of selecting the county. W2 $=$ the inverse of the probability of selecting the classroom within the county. $\mathrm{f} 1$ = a student-level nonresponse adjustment factor calculated by class. $\mathrm{f} 2 \mathrm{a}$ a post-stratification adjustment factor calculated by grade [44]. Continuous variables were summarised as mean \pm standard deviation. The prevalence of suicidal ideation and attempt, and being threatened or injured with a weapon in school, were summarised as percent and 95\% confidence intervals (CI). Weighted prevalence was calculated using the PROC SURVEYFREQ procedure and its difference between groups was compared using Rao-Scott Chi-square test. To evaluate the associations between being threatened or injured with a weapon in school and suicidal ideation and attempt, multivariable logistic regression analyses were performed using the PROC SURVEYLOGISTC procedure, to take into account the complex survey sampling methods. Potential confounding factors, including sociodemographic status, lifestyle factors, academic performance, self-reported health and mental health were adjusted in different models. Odds ratios were calculated using four multivariable logistic regression models. In model 1, odds ratios were adjusted for age ( $\leq 13$ years, $14-15$ years and $\geq$ 16 years), sex (boys and girls), region (urban and rural), and type of school (middle school, academic high school and vocational high school). Model 2 included additional adjustment for parental and maternal education level (middle school or below, high school, college or above and unknown) and parental marital status (married and others). Model 3 included additional adjustment for cigarette smoking (current smoker and non-smoker), alcohol drinking (current drinker and non-drinker), physical activity (none, 1-2 days/week, 3-5 days/week and 6-7 days/week), academic performance (excellent, middle and bad), self-reported health status (very good/good, fair, very $\mathrm{bad} / \mathrm{bad}$ and unknown) and sexual experience (yes and no). Model 4, additionally adjusted for loneliness (never/ occasional, sometimes and often/always) and sadness (yes and no). All statistical tests were two tailed, and $P$ values $<0.05$ were considered statistically significant.

\section{Results}

\section{Descriptive statistics}

A total of 24,157 students from 442 schools were invited to participate. Due to missing or incomplete questionnaires 
or refusal to participate, 23,543 eligible students (response rate 97.5\%) were included in the final analyses. 12,068 (51.3\%) were boys, and mean age was 15.6 years. 12,207 (51.9\%) students were from middle schools, $6477(27.5 \%)$ were from academic high schools, and 4859 (20.6\%) came from vocational high schools.

Compared with those who reported not being threatened or injured, students who reported being threatened or injured with a weapon in school were more likely to be boys $(61.8 \%$ vs. $50.3 \%)$ (Table 1$)$, to come from a rural area $(71.9 \%$ vs. $67.6 \%)$, to have poor academic performance $(31.1 \%$ vs. $26.4 \%)$, to smoke cigarettes $(8.6 \%$ vs. $5.0 \%$ ), to drink alcohol (31.1\% vs. $21.5 \%)$, to describe their health as very bad or bad $(9.0 \%$ vs. $5.2 \%)$, to report previous sexual experiences ( $6.4 \%$ vs. $3.5 \%)$, to feel lonely ( $18.3 \%$ vs. $10.2 \%)$ or sad $(25.8 \%$ vs. $13.9 \%)$, and were less likely to come from intact families $(88.0 \%$ vs. $90.4 \%)$. No significant difference was observed between parental education level and being threatened or injured with a weapon in school $(P>0.05)$.

\section{Prevalence of suicidal ideation and attempt}

The overall prevalence of suicidal ideation was $16.1 \%$ (95\%CI: 15.3-16.9) (Table 2), higher among girls than boys $(19.1 \%$ vs. $13.3 \%)(P<0.0001)$. There was no statistically significant difference in the prevalence of suicidal ideation between urban and rural areas (16.5\% vs. $15.9 \%)$ $(P=0.43)$. The prevalence among students aged $\leq 13$ years, $14-15$ years and $\geq 16$ years was $15.9 \%$ (95\%CI: 14.4-17.4), $17.9 \%$ (95\%CI: $16.7-19.1$ ) and $14.8 \%$ (95\%CI: 13.7-15.9), respectively. The corresponding prevalence among students attending middle school, academic high school and vocational high school was $16.9 \%$ (95\% CI: $15.8-18.0), 16.6 \%$ (95\%CI: $15.3-17.9)$ and $13.7 \%$ (95\%CI: $11.9-15.5)$, respectively $(P=0.0048)$.

The overall prevalence of suicide attempt was 3.6\% (95\%CI: 3.3-4.0) (Table 2), higher among girls than boys $(4.4 \%$ vs. $2.9 \%)(P<.0001)$. No regional difference in suicidal attempt was found (urban: $3.5 \%$ vs. rural: $3.7 \%)(P=0.50)$. The prevalence of suicidal attempt among students aged $\leq 13$ years, $14-15$ years and $\geq 16$ years was $4.1 \%$ (95\%CI: 3.5-4.8), 4.4\% (95\%CI: 3.9-4.9) and $2.8 \%$ (95\%CI: $2.3-3.2)$, respectively. The corresponding figures for students attending middle school, academic high school and vocational high school were 4.4\% (95\%CI: $3.9-4.9)$, $2.4 \%$ (95\%CI: $1.9-2.8$ ) and 3.3\% (95\%CI: $2.6-4.1)$, respectively $(P<.0001)$.

\section{Prevalence of being threatened or injured with a weapon in school}

13.2\% (95\%CI: 11.9-14.5) of students reported being threatened or injured with a weapon in school in the past 12 months (Table 3), higher among boys (15.7\% [95\%CI: 14.2-17.2]) than girls (10.5\% [95\%CI: 9.1-11.8]), and among rural than urban students (13.9\% vs. $11.6 \%)$. The prevalence of being threatened or injured with a weapon in school among students attending middle school, academic high school and vocational high school was $16.7 \%$ (95\%CI: 14.6-18.7), 8.2\% (95\%CI: 7.0-9.4) and 10.9 (95\%CI: 9.2-12.6), respectively $(P<.0001)$. The prevalence of being threatened or injured with a weapon increased with the decreasing age $(P<.0001)$. There was no regional difference in the prevalence of being threatened or injured with a weapon in school among boys (urban: $14.5 \%$ vs. rural: $16.3 \%)(P=0.18)$. However, rural girls had a higher prevalence than their urban counterparts $(11.3 \%$ vs. $8.6 \%)(P=0.02)$.

\section{Logistic regression analysis}

After adjusting for age, sex, region, and type of school (Table 4), compared to those who reported not being threatened or injured, the odds ratios for suicidal ideation and attempt were $2.29(2.08-2.63)$ and $2.93(2.34-$ 3.67) $(P<0.0001$ for all), respectively, among students who reported being threatened or injured with a weapon in school. After further adjustment for parental education level and marital status, lifestyle factors, academic performance, and health status, the corresponding odds ratios were attenuated to $1.89(1.72-2.09)$ and 2.16 (1.72-2.72), respectively $(P<0.0001$ for all). After additional adjustment for mental health (i.e., loneliness and sadness). These associations were further markedly attenuated, with corresponding odds ratios of 1.46 (1.31$1.61)$ and $1.68(1.31-2.13)$, respectively $(P<0.0001$ for all). No sex-difference was observed in the associations of being threatened or injured with a weapon and suicidal ideation $(P=0.61)$ or attempt $(P=0.07)$.

\section{Discussion}

In this provincially representative study of middle and high school students in Zhejiang, China, we examined the prevalence of being threatened or injured with a weapon in school and suicidal ideation and attempt. We identified and quantified the relationship of being threatened or injured with a weapon in school and both suicidal ideation and attempt.

\section{Prevalence of suicidal ideation and attempt}

Suicidal ideation involves a hierarchy of feelings from the thoughts of "Life is not worth living" to more serious articulation of a thought out plan. Suicidal attempt is defined as self-inflicted, potentially injurious behaviours with a nonfatal outcome, for which there was evidence of intent to die [45]. In the present study, the overall prevalence of suicidal ideation and attempt were 16.1 and 3.6\% respectively, lower than the results of the 2015 USA-based YRBS (17.7 and 8.6\%, respectively) [46]. Consistent with results from studies in Western countries 
Table 1 Participant characteristics by history of being threatened or injured with a weapon $(N=23,543)$

\begin{tabular}{|c|c|c|c|c|c|}
\hline Characteristics & $\begin{array}{l}\text { Total } \\
(N=23,543)\end{array}$ & $\begin{array}{l}\text { Without being threatened or injured } \\
(N=20,502)\end{array}$ & $\begin{array}{l}\text { Being threatened or injured } \\
(N=3041)\end{array}$ & $x^{2 a}$ & $P$ value \\
\hline Age range (years) & & & & 60.9 & $<.0001$ \\
\hline$\leq 13$ & $5159(20.9)$ & $4208(19.5)$ & $951(30.5)$ & & \\
\hline $14-15$ & $8030(34.3)$ & $6878(33.8)$ & $1152(37.6)$ & & \\
\hline$\geq 16$ & $10,354(44.8)$ & $9416(46.7)$ & $938(31.9)$ & & \\
\hline Sex & & & & 83.0 & $<.0001$ \\
\hline Boys & $12,068(51.8)$ & $10,196(50.3)$ & $1872(61.8)$ & & \\
\hline Girls & $11,475(48.2)$ & $10,306(49.7)$ & $1169(38.2)$ & & \\
\hline Area & & & & 3.9 & 0.04 \\
\hline Urban & $9022(31.8)$ & 7990 (32.4) & $1032(28.1)$ & & \\
\hline Rural & $14,521(68.2)$ & $12,512(67.6)$ & 2009 (71.9) & & \\
\hline Types of school & & & & 76.5 & $<.0001$ \\
\hline Middle school & $12,207(51.8)$ & $10,210(49.7)$ & $1997(65.4)$ & & \\
\hline Academic high school & $6477(26.1)$ & 5945 (27.6) & $532(16.3)$ & & \\
\hline Vocational high school & $4859(22.1)$ & $4347(22.7)$ & $512(18.3)$ & & \\
\hline Parental marital status & & & & 10.7 & 0.0011 \\
\hline Married & $21,151(90.1)$ & $18,482(90.4)$ & $2669(88.0)$ & & \\
\hline Others & $2392(9.9)$ & $2020(9.6)$ & $372(12.0)$ & & \\
\hline Paternal education level & & & & 1.9 & 0.59 \\
\hline Middle or below & $13,568(60.0)$ & $11,762(59.8)$ & $1806(61.4)$ & & \\
\hline High school & $5100(20.8)$ & $4457(20.9)$ & $643(19.6)$ & & \\
\hline College or above & $3129(11.4)$ & $2756(11.5)$ & $373(11.1)$ & & \\
\hline Unknown & $1746(7.8)$ & $1527(7.8)$ & $219(7.9)$ & & \\
\hline Maternal education level & & & & 0.20 & 0.98 \\
\hline Middle or below & $14,530(63.9)$ & $12,627(64.0)$ & $1903(63.5)$ & & \\
\hline High school & $4363(17.7)$ & 3802 (17.6) & $561(18.1)$ & & \\
\hline College or above & $2736(10.0)$ & $2403(10.0)$ & $333(10.0)$ & & \\
\hline Unknown & $1914(8.4)$ & $1670(8.4)$ & $244(8.4)$ & & \\
\hline Physical activity (d/wk) & & & & 10.5 & 0.01 \\
\hline 0 & $4883(21.5)$ & $4306(21.8)$ & $577(19.7)$ & & \\
\hline $1-2$ & $5690(24.8)$ & $4995(25.1)$ & $695(23.1)$ & & \\
\hline $3-5$ & $8050(33.0)$ & 6979 (32.9) & $1071(34.1)$ & & \\
\hline $6-7$ & $4920(20.7)$ & $4222(20.2)$ & $698(23.1)$ & & \\
\hline Academic performance & & & & 18.6 & $<.0001$ \\
\hline Excellent & $5448(22.5)$ & $4782(22.8)$ & $666(20.7)$ & & \\
\hline Middle & $11,765(50.5)$ & $10,331(50.8)$ & $1434(48.2)$ & & \\
\hline Bad & $6330(27.0)$ & $5389(26.4)$ & $941(31.1)$ & & \\
\hline Current smoking & $1247(5.5)$ & $984(5.0)$ & $263(8.6)$ & 43.8 & $<.0001$ \\
\hline Current drinking & $5345(22.8)$ & $4382(21.5)$ & $963(31.1)$ & 49.1 & $<.0001$ \\
\hline Self-reported health & & & & 90.0 & $<.0001$ \\
\hline Very good/good & $12,415(51.8)$ & $11,002(52.7)$ & $1413(45.8)$ & & \\
\hline Fair & $9563(41.4)$ & $8256(41.1)$ & $1307(43.4)$ & & \\
\hline Very bad/bad & $1293(5.7)$ & $1029(5.2)$ & $264(9.0)$ & & \\
\hline Unknown & $272(1.1)$ & $215(1.0)$ & $57(1.8)$ & & \\
\hline
\end{tabular}


Table 1 Participant characteristics by history of being threatened or injured with a weapon $(N=23,543)$ (Continued)

\begin{tabular}{|c|c|c|c|c|c|}
\hline Characteristics & $\begin{array}{l}\text { Total } \\
(N=23,543)\end{array}$ & $\begin{array}{l}\text { Without being threatened or injured } \\
(N=20,502)\end{array}$ & $\begin{array}{l}\text { Being threatened or injured } \\
(N=3041)\end{array}$ & $x^{2 a}$ & $P$ value \\
\hline Sexual experience & 861 (3.9) & 669 (3.5) & $192(6.4)$ & 35.1 & $<.0001$ \\
\hline Loneliness & & & & 220.7 & $<.0001$ \\
\hline Never/occasional & $15,122(64.1)$ & $13,574(66.2)$ & 1548 (49.9) & & \\
\hline Sometimes & $5783(24.7)$ & 4844 (23.6) & 939 (31.8) & & \\
\hline Often/always & $2638(11.2)$ & $2084(10.2)$ & $554(18.3)$ & & \\
\hline Sadness & $3676(15.4)$ & $2893(13.9)$ & 783 (25.8) & 142.5 & $<.0001$ \\
\hline
\end{tabular}

Number in brackets are weighted proportions. ${ }^{a}$ Rao-Scott Chi-Square

$[35,46]$, our study indicated that the prevalence of suicidal ideation and attempt were higher among girls than among boys. Interestingly, national mortality surveillance in China demonstrated that men had a higher suicide rate than women in the general population [3]. This discrepancy may be explained by women adopting non-lethal means to attempt suicide $[47,48]$.

\section{Prevalence of being threatened or injured with a weapon in school}

In the present study, $13.2 \%$ of students reported being threatened or injured with a weapon in school during the past 12 months, more than twice the reported prevalence in the USA (6.0\%) [30]. This suggests that being threatened or injured with a weapon in school is common in China. This highlights the need for both the public and government to focus on the prevention of school bullying. Consistent with the previous US study [30], our study found that the prevalence of being threatened or injured with a weapon in school was higher among boys than girls. The possible explanation was that boys are more likely to be physically bullied [49]. While girls are more likely to be exposed to more covert forms of bullying (e.g., gossiping and social exclusion) [50]. Our study demonstrated that rural students were more likely to be threatened or injured with a weapon than urban students. There are several possible explanations for this phenomenon. First, there were more left-behind children in rural areas. In the absence of family care, children may be inclined to be violent [51]. Second, schools in rural areas may focus less on prevention and management of school bullying in comparison with schools in urban areas.

\section{Association of being threatened or injured with a weapon and suicide ideation and attempt}

A 2013 meta-analysis of 41 studies found that being bullied was positively associated with suicidal ideation $(\mathrm{OR}=2.34$, 95\%CI: 2.03-2.69) and suicide attempt among adolescents $(\mathrm{OR}=2.94,95 \% \mathrm{CI}: 2.36-3.67)$ [31].

Table 2 Weighted prevalence of suicidal ideation and attempt by different subgroups

\begin{tabular}{|c|c|c|c|c|c|c|}
\hline \multirow[t]{2}{*}{ Characteristics } & \multicolumn{3}{|l|}{ Suicidal ideation } & \multicolumn{3}{|l|}{ Suicidal attempt } \\
\hline & Prevalence $(95 \% \mathrm{Cl})^{\mathrm{a}}$ & $x^{2 b}$ & $P$ value & Prevalence $(95 \% \mathrm{Cl})^{a}$ & $x^{2 b}$ & $P$ value \\
\hline Age range (years) & & 16.8 & 0.0002 & & 29.4 & $<.0001$ \\
\hline$\leq 13$ & $15.9(14.4-17.4)$ & & & $4.1(3.5-4.8)$ & & \\
\hline $14-15$ & $17.9(16.7-19.1)$ & & & $4.4(3.9-4.9)$ & & \\
\hline$\geq 16$ & $14.8(13.7-15.9)$ & & & $2.8(2.3-3.2)$ & & \\
\hline Sex & & 88.2 & $<.0001$ & & 45.5 & $<.0001$ \\
\hline Boys & $13.3(12.3-14.2)$ & & & $2.9(2.5-3.2)$ & & \\
\hline Girls & $19.1(18.1-20.2)$ & & & $4.4(3.9-4.9)$ & & \\
\hline Area & & 0.6 & 0.43 & & 0.45 & 0.50 \\
\hline Urban & $16.5(15.3-17.8)$ & & & $3.5(3.0-3.9)$ & & \\
\hline Rural & $15.9(14.9-16.9)$ & & & $3.7(3.2-4.2)$ & & \\
\hline Types of school & & 10.7 & 0.0048 & & 27.2 & $<.0001$ \\
\hline Middle school & $16.9(15.8-18.0)$ & & & $4.4(3.9-4.9)$ & & \\
\hline Academic high school & $16.6(15.3-17.9)$ & & & $2.4(1.9-2.8)$ & & \\
\hline Vocational high school & $13.7(11.9-15.5)$ & & & $3.3(2.6-4.1)$ & & \\
\hline
\end{tabular}

aased on the weighted data. ${ }^{\text {b }}$ : Rao-Scott Chi-Square, $\mathrm{Cl}$ Confidence Interval 
Table 3 Weighted prevalence of being threatened or injured with a weapon in school by different subgroups

\begin{tabular}{|c|c|c|c|c|c|c|c|c|c|}
\hline \multirow[t]{2}{*}{ Characteristics } & \multicolumn{3}{|l|}{ Overall } & \multicolumn{3}{|l|}{ Boys } & \multicolumn{3}{|l|}{ Girls } \\
\hline & Prevalence $(95 \% \mathrm{Cl})^{\mathrm{a}}$ & $x^{2}$ & $P$ value & Prevalence $(95 \% \mathrm{Cl})^{a}$ & $x^{2}$ & $P$ value & Prevalence $(95 \% \mathrm{Cl})^{a}$ & $x^{2}$ & $P$ value \\
\hline Age range (years) & & $289.5^{c}$ & $<.0001$ & & $154.3^{c}$ & $<.0001$ & & $135.0^{c}$ & $<.0001$ \\
\hline$\leq 13$ & $19.2(15.9-22.4)$ & & & $22.5(18.8-26.2)$ & & & 15.5 (12.2-18.8) & & \\
\hline $14-15$ & $14.5(12.4-16.5)$ & & & $17.0(14.9-19.1)$ & & & $11.7(9.5-13.9)$ & & \\
\hline$\geq 16$ & $9.4(8.4-10.4)$ & & & $11.5(10.2-12.8)$ & & & $7.1(5.8-8.5)$ & & \\
\hline Area & & $3.95^{\mathrm{b}}$ & 0.04 & & $1.76^{\mathrm{b}}$ & 0.18 & & $5.5^{b}$ & 0.02 \\
\hline Urban & $11.6(10.3-12.9)$ & & & $14.5(12.9-16.1)$ & & & $8.6(7.1-10.0)$ & & \\
\hline Rural & $13.9(12.1-15.8)$ & & & $16.3(14.2-18.3)$ & & & $11.3(9.5-13.2)$ & & \\
\hline Types of school & & $76.5^{\mathrm{b}}$ & $<.0001$ & & $64.0^{\mathrm{b}}$ & $<.0001$ & & $32.6^{\mathrm{b}}$ & $<.0001$ \\
\hline Middle school & $16.7(14.6-18.7)$ & & & $19.6(17.3-21.8)$ & & & $13.4(11.3-15.6)$ & & \\
\hline Academic high school & $8.2(7.0-9.4)$ & & & $10.3(8.7-11.9)$ & & & $6.2(4.9-7.5)$ & & \\
\hline Vocational high school & $10.9(9.2-12.6)$ & & & $12.8(10.9-14.8)$ & & & $8.7(6.2-11.3)$ & & \\
\hline
\end{tabular}

${ }^{\mathrm{a}}$ Based on the weighted data. ${ }^{\mathrm{b}}$ : Rao-Scott Chi-Square, ${ }^{\mathrm{c}}$ :Trend for Chi-Square, Cl Confidence Interval

However, this study failed to ascertain the associations between different types of bullying victimization and suicidal behaviours. A longitudinal study of 2464 Norwegian adolescents aged $12-15$ years observed that exposure to bullying during adolescence increased the risk of both suicidal ideation and attempt among boys and girls, and this effect persisted into young adulthood [52]. Another cohort study of 5302 Finnish children showed that the association between being bullied at age 8 years and later suicidal attempts varied by sex. After controlling for conduct and depression, the association remained significant among girls, but not among boys [53]. Our study found that being threatened or injured with a weapon in school was positively associated with risk of suicidal attempt among both girls and boys. The mechanisms underlying the associations with suicidal ideation and attempt remain unclear. One explanation may be that being threatened or injured represents a serious physical victimization and could cause depression, which, in turn, has been closely associated with suicidal ideation and attempt [54, 55]. Previous studies found that students who were once victims of bullying were more likely to experience depression [56, 57], and Brunstein Klomek et al. found a bidirectional association between victimization and depression [38].

There are a number of important implications of the findings of our study for prevention of adolescent suicide. First, although the Chinese government introduced a strategy for strengthening the comprehensive management of bullying, and launched an anti-bullying campaign in primary and middle schools in 2017, prevention of school bullying needs to be further reinforced in China. Students should be taught how to deal with school bullying, including being threatened or injured by others with a weapon. Second, students who report being threatened or injured with a weapon should be identified as being at-risk, and suicide prevention should be an important component of psychological support and interventions provided to these students.

\section{Strengths and limitations}

The strengths of the current study include the provincially representative sample, a high response rate and a standardized procedure. The study questionnaire collates data on a range of socio-demographic, behavioral and mental health factors, which allowed us to better control confounding. Our study, however, had several limitations.

Table 4 Adjusted odds ratios of suicidal behaviours associated with being threatened or injured with a weapon among school students in China

\begin{tabular}{|c|c|c|c|c|c|c|c|c|}
\hline & \multicolumn{4}{|l|}{ Suicidal ideation } & \multicolumn{4}{|l|}{ Suicidal attempt } \\
\hline & Total & Boys & Girls & $P^{a}$ & Total & Boys & Girls & $P^{a}$ \\
\hline Model 1 & $2.29(2.08-2.63)$ & $2.26(1.96-2.62)$ & $2.34(2.04-2.68)$ & 0.53 & $2.93(2.34-3.67)$ & $2.56(1.89-3.46)$ & $3.29(2.49-4.35)$ & 0.11 \\
\hline Model 2 & $2.27(2.06-2.51)$ & $2.24(1.94-2.59)$ & $2.31(2.01-2.66)$ & 0.54 & $2.89(2.30-3.63)$ & $2.55(1.88-3.45)$ & $3.23(2.43-4.29)$ & 0.11 \\
\hline Model 3 & $1.89(1.72-2.09)$ & $1.89(1.63-2.17)$ & $1.91(1.65-2.21)$ & 0.56 & $2.16(1.72-2.72)$ & $1.89(1.37-2.62)$ & $2.45(1.87-3.22)$ & 0.07 \\
\hline Model 4 & $1.46(1.31-1.61)$ & $1.46(1.25-1.70)$ & $1.47(1.26-1.71)$ & 0.61 & $1.68(1.31-2.13)$ & $1.43(1.02-2.00)$ & $1.93(1.44-2.58)$ & 0.07 \\
\hline
\end{tabular}

Model 1, odds ratios were adjusted for age, sex, region, type of school. Model 2, additionally adjusted for parental and maternal education level and parental marital status. Model 3, additionally adjusted for cigarette smoking, alcohol drinking, physical activity academic performance, self-reported health status, sexual experience. Model 4 , additionally adjusted for loneliness and sadness. ${ }^{\text {a }}$ for gender heterogeneity 
First, the cross-sectional design limits establishment of the temporal relationship of being threatened or injured with a weapon in school with suicidal ideation and attempt, and it is not possible to establish the causality of the relationship. Second, all data were self-reported; some information might not be accurately reported due to recall or social desirability biases. Physical bullying in school is relatively more common and familiar to teachers and parents. Non-physical bullying (e.g., social exclusion) is less visible and more easily neglected. In addition, with the rapid development of Internet and electronic technology, children and adolescents are more likely to be exposed to bullying in an electronic context (e.g., e-mail, blogs, instant messages, text messages). Hence, longitudinal studies are needed to explore the associations of non-physical and physical bullying with suicidal ideation and attempt.

\section{Conclusions}

Despite its limitations, our study clearly described the associations of being threatened or injured with a weapon in school and suicidal ideation and attempt among middle and high school students in Zhejiang China. We found that being threatened or injured with a weapon in school was common, and was strongly associated with both suicidal ideation and attempt. Preventive measures for physical bullying among middle and high school students need to be reinforced in Zhejiang China, and efforts to prevent adolescent suicide may need to address school bullying. Suicide prevention should be an important component of psychological intervention for threatened or injured students.

\section{Abbreviations \\ CDC: Disease Control and Prevention; Cl: Confidence Intervals; NCDs: Non- Communicable Diseases; SD: Standard Deviation; USA: United States of America; WHO: World Health Organization; YRBS: Youth Risk Behaviour Survey}

\section{Acknowledgements}

We express our gratitude to all the students, parents, teachers and local officials for their participation, assistance and co-operation.

\section{Funding}

The work was supported by grant (2016YFC0900502) from National Key Research and Development Program of China. The funding sponsors have no role in design and conduct of the study; collection, analyses, and interpretation of the results.

\section{Availability of data and materials}

The datasets used and/or analyzed during the current study are available from HW on reasonable request.

\section{Authors' contributions}

HW and MY designed the study. HW collected and analyzed the data. JZ was involved in data interpretation. HD and FB provided important comments on the manuscript and revised the manuscript. All the authors have read and approved the final submitted version.

\section{Ethics approval and consent to participate}

The study is approved by the ethics committee of Zhejiang Provincial Centre for Disease Control and Prevention. Written consent form was given to all students and their guardians in the 2 weeks prior to the survey, and was collected after their signature. The students will not be investigated, if they or their guardians refused to sign their names.

\section{Consent for publication}

Not applicable.

\section{Competing interests}

The authors declare that they have no competing interests.

\section{Publisher's Note}

Springer Nature remains neutral with regard to jurisdictional claims in published maps and institutional affiliations.

\section{Author details}

'Department of NCDs Control and Prevention, Zhejiang Provincial Center for Diseases Control and Prevention, \#3399 Binsheng road, Binjiang District, Hangzhou 310051, Zhejiang Province, China. ${ }^{2}$ Clinical Trial Service Unit \& Epidemiological Studies Unit (CTSU), Nuffield Department of Population Health, University of Oxford, Oxford OX3 7LF, UK. ${ }^{3}$ Medical Research Council Population Health Research Unit, Nuffield Department of Population Health, University of Oxford, Oxford OX3 7LF, UK.

Received: 4 July 2018 Accepted: 5 December 2018

Published online: 27 December 2018

\section{References}

1. Pridmore $\mathrm{S}$, Auchincloss $\mathrm{S}$. Preventing suicide: a global imperative. Australas Psychiatry. 2015;23(1):81-2.

2. Yip PS, Liu KY, Hu J, Song XM. Suicide rates in China during a decade of rapid social changes. Soc Psychiatry Psychiatr Epidemiol. 2005;40(10):792-8.

3. Sha F, Chang Q, Law YW, Hong Q, Yip PSF. Suicide rates in China, 20042014: comparing data from two sample-based mortality surveillance systems. BMC Public Health. 2018;18(1):239.

4. Gao X, Wang LH, Jin Y, Ye PP, Yang L, Er YL, Deng X, Wang Y, Duan LL. Disease burden caused by suicide in the Chinese population, in 1990 and 2013. Zhonghua Liu Xing Bing Xue Za Zhi. 2017;38(10):1325-9.

5. Chen R, An J, Ou J. Suicidal behaviour among children and adolescents in China. Lancet Child Adolesc Health. 2018;2(8):551-3.

6. Phillips MR, Yang G, Zhang Y, Wang L, Ji H, Zhou M. Risk factors for suicide in China: a national case-control psychological autopsy study. Lancet. 2002; 360(9347):1728-36.

7. Phillips MR, Li X, Zhang Y. Suicide rates in China, 1995-99. Lancet. 2002; 359(9309):835-40,

8. Zhang J, Conwell Y, Zhou L, Jiang C. Culture, risk factors and suicide in rural China: a psychological autopsy case control study. Acta Psychiatr Scand. 2004:110(6):430-7.

9. Borowsky IW, Ireland M, Resnick MD. Adolescent suicide attempts: risks and protectors. Pediatrics. 2001;107(3):485-93.

10. Bertolote JM, Fleischmann A, De Leo D, Phillips MR, Botega NJ, Vijayakumar L, De Silva D, Schlebusch L, Nguyen VT, Sisask M, et al. Repetition of suicide attempts: data from emergency care settings in five culturally different lowand middle-income countries participating in the WHO SUPRE-MISS study. Crisis. 2010;31 (4):194-201.

11. Chang WW, Yao YS, Yuan H, Chen BF, Liang YL, Chen Y, Song JG, Li J, Zhu Y. Prevalence of suicide ideation among middle school students in China: a systematic analysis of studies between 2000 and 2012. Zhonghua Liu Xing Bing Xue Za Zhi. 2013;34(5):515-9.

12. Cuadrado C, Zitko P, Covarrubias T, Hernandez D, Sade C, Klein C, Gomez A. Association between adolescent suicide and sociodemographic factors in Chile: cross-sectional ecological study. Crisis. 2015;36(4):281-90.

13. Blum RW, Beuhring T, Shew ML, Bearinger $L H$, Sieving RE, Resnick MD. The effects of race/ethnicity, income, and family structure on adolescent risk behaviors. Am J Public Health. 2000;90(12):1879-84.

14. Darvishi N, Farhadi M, Haghtalab T, Poorolajal J. Alcohol-related risk of suicidal ideation, suicide attempt, and completed suicide: a meta-analysis. PLoS One. 2015;10(5):e0126870.

15. Sibold J, Edwards E, Murray-Close D, Hudziak JJ. Physical activity, sadness, and suicidality in bullied US adolescents. J Am Acad Child Adolesc Psychiatry. 2015;54(10):808-15. 
16. Silva RJ, dos Santos FA, Soares NM, Pardono E. Suicidal ideation and associated factors among adolescents in northeastern Brazil. Sci World J. 2014; 2014:450943.

17. Maslow GR, Dunlap K, Chung RJ. Depression and suicide in children and adolescents. Pediatr Rev. 2015;36(7):299-308 quiz 309-210.

18. Bennardi M, Caballero FF, Miret M, Ayuso-Mateos JL, Haro JM, Lara E, Arensman E, Cabello M. Longitudinal relationships between positive affect, loneliness, and suicide ideation: age-specific factors in a general population. Suicide Life Threat Behav. 2017. https://doi.org/10.1111/sltb.12424.

19. Zhao S, Zhang J. Suicide risks among adolescents and young adults in rural China. Int J Environ Res Public Health. 2014;12(1):131-45.

20. Bridge JA, Goldstein TR, Brent DA. Adolescent suicide and suicidal behavior. J Child Psychol Psychiatry. 2006;47(3-4):372-94.

21. Sorberg Wallin A, Zeebari Z, Lager A, Gunnell D, Allebeck P, Falkstedt D. Suicide attempt predicted by academic performance and childhood IQ: a cohort study of 26000 children. Acta Psychiatr Scand. 2018; 137(4):277-86.

22. Centers for Disease Control and Prevention. Prevent Bullying [https://www cdc.gov/features/prevent-bullying/index.html]. Accessed 27 Mar 2017.

23. Curelaru M, lacob I, Abalasei B. School bullying: definition, characteristics, and intervention strategies. Revista de Cercetare si Interventie Sociala. 2009;26:7.

24. Due P, Holstein BE, Lynch J, Diderichsen F, Gabhain SN, Scheidt P, Currie C. Health behaviour in school-aged children bullying working $G$ : bullying and symptoms among school-aged children: international comparative cross sectional study in 28 countries. Eur J Pub Health. 2005;15(2):128-32.

25. Reijntjes A, Kamphuis $\mathrm{JH}$, Prinzie P, Telch MJ. Peer victimization and internalizing problems in children: a meta-analysis of longitudinal studies. Child Abuse Negl. 2010;34(4):244-52.

26. Brito CC, Oliveira MT. Bullying and self-esteem in adolescents from public schools. J Pediatr. 2013;89(6):601-7.

27. Nielsen MB, Tangen T, Idsoe T, Matthiesen SB, Magerøy N. Post-traumatic stress disorder as a consequence of bullying at work and at school. A literature review and meta-analysis. Aggress Violent Behav. 2015;21:17-24.

28. Thomas HJ, Chan GC, Scott JG, Connor JP, Kelly AB, Williams J. Association of different forms of bullying victimisation with adolescents' psychological distress and reduced emotional wellbeing. Aust N Z J Psychiatry. 2016 50(4):371-9.

29. Bender D, Losel F. Bullying at school as a predictor of delinquency, violence and other anti-social behaviour in adulthood. Crim Behav Ment Health. 2011;21(2):99-106.

30. Kann L, McManus T, Harris WA, Shanklin SL, Flint KH, Queen B, Lowry R, Chyen D, Whittle L, Thornton J, et al. Youth risk behavior surveillance United States, 2017. MMWR Surveill Summ. 2018;67(8):1-114.

31. Holt MK, Vivolo-Kantor AM, Polanin JR, Holland KM, DeGue S, Matjasko JL, Wolfe M, Reid G. Bullying and suicidal ideation and behaviors: a meta-analysis. Pediatrics. 2015:135(2):e496-509.

32. Bhatta MP, Shakya S, Jefferis E. Association of being bullied in school with suicide ideation and planning among rural middle school adolescents. J Sch Health. 2014;84(11):731-8.

33. Sampasa-Kanyinga $\mathrm{H}$, Roumeliotis $\mathrm{P}, \mathrm{Xu} \mathrm{H}$. Associations between cyberbullying and school bullying victimization and suicidal ideation, plans and attempts among Canadian schoolchildren. PLoS One. 2014; 9(7):e102145.

34. Bang YR, Park JH. Psychiatric disorders and suicide attempts among adolescents victimized by school bullying. Australas Psychiatry. 2017; 25(4):376-80.

35. Barzilay S, Brunstein Klomek A, Apter A, Carli V, Wasserman C, Hadlaczky G, Hoven CW, Sarchiapone M, Balazs J, Kereszteny A, et al. Bullying victimization and suicide ideation and behavior among adolescents in Europe: a 10-country study. J Adolesc Health. 2017;61(2):179-86.

36. Kim YS, Koh YJ, Leventhal B. School bullying and suicidal risk in Korean middle school students. Pediatrics. 2005;115(2):357-63.

37. van der Wal MF, de Wit CA, Hirasing RA. Psychosocial health among young victims and offenders of direct and indirect bullying. Pediatrics. 2003;111(6 Pt 1):1312-7.

38. Brunstein Klomek A, Barzilay S, Apter A, Carli V, Hoven CW, Sarchiapone M, Hadlaczky G, Balazs J, Kereszteny A, Brunner R, et al. Bi-directional longitudinal associations between different types of bullying victimization, suicide ideation/ attempts, and depression among a large sample of European adolescents. J Child Psychol Psychiatry. 2018. https://doi.org/10.1111/jcpp.12951.
39. Hong L, Guo L, Wu H, Li P, Xu Y, Gao X, Deng J, Huang G, Huang J, Lu C. Bullying, depression, and suicidal ideation among adolescents in the Fujian Province of China: a cross-sectional study. Medicine (Baltimore). 2016:95(5):e2530.

40. Wang H, Hu R, Zhong J, Du H, Fiona B, Wang M, Yu M. Binge drinking and associated factors among school students: a cross-sectional study in Zhejiang Province, China. BMJ Open. 2018;8(4):e021077.

41. Centers for Disease Control and Prevention . 2017 State and Local Youth Risk Behavior Survey; [https://www.cdc.gov/healthyyouth/data/yrbs/ questionnaires.htm].

42. World Health Organization.Global school-based students health survey(GSHS) [http://www.who.int/ncds/surveillance/gshs/nepal/en/]. Accessed 22 Mar 2017.

43. Wang $\mathrm{H}$, Zhong J, Hu R, Fiona B, Yu M, Du H. Prevalence of high screen time and associated factors among students: a cross-sectional study in Zhejiang, China. BMJ Open. 2018:8(6):e021493.

44. Pengpid S, Peltzer K. Alcohol use and associated factors among adolescent students in Thailand. West Indian Med J. 2012:61(9):890-6.

45. Liu BP, Wang XT, Jia CX. Suicide attempters with high and low suicide intent: different populations in rural China. Psychiatry Res. 2017;251:176-81.

46. Kann L, McManus T, Harris WA, Shanklin SL, Flint KH, Hawkins J, Queen B, Lowry R, Olsen EO, Chyen D, et al. Youth risk behavior surveillance - United States, 2015. MMWR Surveill Summ. 2016:65(6):1-174.

47. Large MM, Nielssen OB. Suicide in Australia: meta-analysis of rates and methods of suicide between 1988 and 2007. Med J Aust. 2010;192(8):432-7.

48. Schrijvers DL, Bollen J, Sabbe BG. The gender paradox in suicidal behavior and its impact on the suicidal process. J Affect Disord. 2012;138(1-2):19-26.

49. Undheim AM, Sund AM. Prevalence of bullying and aggressive behavior and their relationship to mental health problems among 12- to 15-year-old Norwegian adolescents. Eur Child Adolesc Psychiatry. 2010;19(11):803-11.

50. Craig WM, Pepler DJ. Identifying and targeting risk for involvement in bullying and victimization. Can J Psychiatr. 2003:48(9):577-82.

51. Bakker $C$, Elings-Pels $M$, Reis $M$. The impact of migration on children in the Caribbean. Bridgetown: UNICEF; 2011

52. Sigurdson JF, Undheim AM, Wallander JL, Lydersen S, Sund AM. The longitudinal Association of Being Bullied and Gender with suicide ideations, self-harm, and suicide attempts from adolescence to young adulthood: a cohort study. Suicide Life Threat Behav. 2018:48(2):169-82.

53. Klomek AB, Sourander A, Niemela S, Kumpulainen K, Piha J, Tamminen T, Almqvist F, Gould MS. Childhood bullying behaviors as a risk for suicide attempts and completed suicides: a population-based birth cohort study. J Am Acad Child Adolesc Psychiatry. 2009;48(3):254-61.

54. Hawton K, Casanas ICC, Haw C, Saunders K. Risk factors for suicide in individuals with depression: a systematic review. J Affect Disord. 2013; 147(1-3):17-28.

55. Ribeiro JD, Huang X, Fox KR, Franklin JC. Depression and hopelessness as risk factors for suicide ideation, attempts and death: meta-analysis of longitudinal studies. Br J Psychiatry. 2018;212(5):279-86.

56. Bond L, Carlin JB, Thomas L, Rubin K, Patton G. Does bullying cause emotional problems? A prospective study of young teenagers. BMJ. 2001; 323(7311):480-4

57. Brunstein Klomek A, Marrocco F, Kleinman M, Schonfeld IS, Gould MS. Bullying, depression, and suicidality in adolescents. J Am Acad Child Adolesc Psychiatry. 2007:46(1):40-9.

Ready to submit your research? Choose BMC and benefit from:

- fast, convenient online submission

- thorough peer review by experienced researchers in your field

- rapid publication on acceptance

- support for research data, including large and complex data types

- gold Open Access which fosters wider collaboration and increased citations

- maximum visibility for your research: over $100 \mathrm{M}$ website views per year

At BMC, research is always in progress.

Learn more biomedcentral.com/submissions 